The atmospheric bridge communicated the $\delta^{13} \mathrm{C}$ decline during the last deglaciation to the global upper ocean

Jun Shao et al.

Correspondence to: Jun Shao (junshao@usc.edu)

The copyright of individual parts of the supplement might differ from the article licence. 


\section{cGENIE $\delta^{13} C_{(D I C)}$ tracer decomposition and attribution error analysis}

\section{Model summary and primary tracer overview}

We employ the open source intermediate complexity Earth system model cGENIE.muffin ( DOI:10.5281/zenodo.4903423) to decompose the different components comprising the stable carbon isotopic $\left(\delta^{13} \mathrm{C}\right)$ composition of dissolved inorganic carbon (DIC) in the ocean. As implemented here, cGENIE comprises: (1) a 3D ocean circulation model component configured on a $36 \times 36$ equal are grid, with 16 non-equally spaced vertical levels in the ocean, (2) a 2D energy-moisture balance model ('EMBM') component, and (3) a 2D dynamic-thermodynamic sea-ice model component. The absence of a dynamical atmospheric GCM component then requires that (fixed, annual average) 2D fields of wind stress and speed are applied, which are re-gridded from observations, plus a zonally-average profile of planetary albedo is applied. Greenhouse gas feedback on climate is implemented by applying a top of the atmosphere anomaly in radiative forcing according to the relative deviation of atmospheric $\mathrm{CO}_{2}$ from a reference value of $278 \mathrm{ppm}$. These three individual components, their coupling, plus details of the simplified atmospheric component and associated climate feedbacks, are described in Marsh et al. [2011] (and references therein).

The basic physics parameter calibration of the climate model component is as per Cao et al. [2009]. Our implementation of cGENIE includes a relatively complete description of the cycling of carbon and oxygen in the ocean plus exchange with the atmosphere, as described in Ridgwell et al. [2007] and Cao et al. [2009]. In addition, the carbon isotopic (both $\delta^{13} \mathrm{C}$ and radiocarbon $\left(\Delta^{14} \mathrm{C}\right)$ ) composition of all the carbon pools plus associated fractionations are represented, as described in Ridgwell et al. [2007] with additional description and evaluation in Kirtland Turner and Ridgwell [2016].

25 In addition to basic carbon (DIC and $\delta^{13} \mathrm{C}_{(\mathrm{DIC})}$ ), alkalinity, single nutrient $\left(\mathrm{PO}_{4}\right)$, oxygen (and sulphate) cycling in the model, we include a variety of diagnostic tracers to decompose all of the 'components' of DIC and its $\delta^{13} \mathrm{C}$ signature. (Note that the tracer notation given here follows that of the model and associated documentation, and can deviate from that of the main paper. Equivalents are given when needed.) These explicitly simulated tracers are:

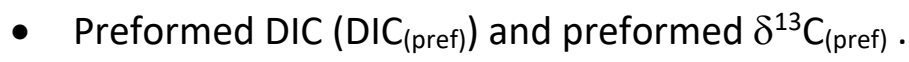

The values of these tracers are reset to the respective concentrations of DIC and

${ }^{13} \mathrm{C}_{\text {(DIC) }}$ at the ocean surface at each time-step, and thereafter are carried conservatively (no loss of gain of carbon can occur) by ocean circulation.

- Regenerated DIC from organic matter, DIC (Csoft) (also known as ' $\mathrm{C}_{\text {soft }}$ '), and its associated isotopic signature $\left(\delta^{13} \mathrm{C}_{(\mathrm{Csoft})}\right)$.

In this, the value of these tracers is reset to zero at the ocean surface at each timestep. In the ocean interior, respired carbon (and for $\delta^{13} \mathrm{C}_{(\mathrm{Csoft})}$, the ${ }^{13} \mathrm{C}$ component of respired carbon) associated with remineralization of both particulate and dissolved organic matter is added to the tracer field. The tracer fields are also subject to ocean circulation. Note that because isotopes are carried explicitly as concentrations in cGENIE (and 
delta $(\delta)$ values only generated in conjunction with bulk concentrations for results output), the $\delta^{13} \mathrm{C}_{\text {(csoft) }}$ tracer is simulated as a concentration and exactly as per $\mathrm{DIC}_{\text {(Csoft) }}$ and does not need to be e.g. normalized to a fractional contribution to $\delta^{13} C_{\text {(DIC) }}$ (as is required e.g. for the AOU-derived tracer, described subsequently).

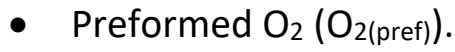

The value of this tracer is reset to the concentration of dissolved $\mathrm{O}_{2}$ at the ocean surface at each time-step, and thereafter carried conservatively (no loss of gain of dissolved oxygen can occur) by ocean circulation.

- Preformed $\mathrm{PO}_{4}\left(\mathrm{PO}_{4(\text { pref })}\right)$.

The value of this tracer is reset to the concentration of dissolved $\mathrm{PO}_{4}$ at the ocean surface at each time-step, and thereafter carried conservatively (no loss of gain of dissolved phosphate can occur) by ocean circulation.

The final component of $\mathrm{DIC}$ - carbon released through the dissolution of $\mathrm{CaCO}_{3}$ in the water 55 column (and released from the upper sediments) - $\mathrm{DIC}_{(\mathrm{CaCO})}$ - is calculated by difference (of DIC vs. DIC (pref) plus DIC (Csoft)) and is not simulated here explicitly as a separate tracer. (Ditto for $\delta^{13} C_{(\text {(CaCO3). })}$

\section{Steady state experiment description and basic tracer analysis}

We start by performing a decomposition analysis of the carbon components, using a standard preindustrial configuration of CGENIE (Cao et al. [2009]) that is run for 10,000 years to steadystate. The results of this are shown broken down by basin as zonally-averaged concentrations shown in Figure S2. Notable here is the relatively insignificant contribution of $\mathrm{DIC}_{(\mathrm{CaCO}) \text {, }}$ particularly in the upper ca. $1000 \mathrm{~m}$ of the water column, where it typically contributes no more than about $10 \mu \mathrm{mol} \mathrm{kg}{ }^{-1} \mathrm{DIC}$. (This will be important later in justifying the various assumptions inherent in the AOU-based analysis of the LOVECLIM experiment.)

In Figure S3, we show the corresponding basin zonal means of $\delta^{13} \mathrm{C}_{\text {(DIC) }}$ simulated by CGENIE in the preindustrial ocean, together with the 3 components that contribute to the net distribution. Notable again here is the weak contribution that can be ascribed to the dissolution of $\mathrm{CaCO}_{3}$. Indeed, in the upper ca. $1000 \mathrm{~m}$ of the water column, the (positive) contribution of $\delta^{13} \mathrm{C}_{\text {(СасО) }}$ is generally less than about $0.05 \%$, compared to a contribution from $\delta^{13} \mathrm{C}_{\text {(Csoft) }}$ that can exceed (in magnitude) $-2.0 \%$ and to a $\delta^{13} \mathrm{C}_{\text {(pref) }}$ contribution lying between ca. 1.5 and $2.5 \%$. Note the different (to $\delta^{13} \mathrm{C}_{(\mathrm{Csoft})}$ ) color scale for $\delta^{13} \mathrm{C}_{(\mathrm{CaCO})}$ and that the surface (and convected-to-depth in the North Atlantic) apparent high values (purple colors) are an artifact of the differencing of DIC and ${ }^{13} \mathrm{C}_{\text {(DIC) }}$ concentrations used in calculating $\delta^{13} \mathrm{C}_{\text {(CaCO3) }}$ (i.e. at close-tozero values for $\mathrm{DIC}_{(\mathrm{CaCO})}$ spurious apparent isotopic values can arise).

In a final, simple numerical check of this diagnostic tracer scheme (not shown), we re-run the 10,000 year preindustrial experiment but with the production of $\mathrm{CaCO}_{3}$ at the ocean surface disabled, i.e. in the complete absence of any $\delta^{13} \mathrm{C}_{(\mathrm{CaCO})}$ component to $\delta^{13} \mathrm{C}_{(\mathrm{DIC}) \text {. From this we }}$ confirm, as expected, that DIC $=\mathrm{DIC}_{(\text {pref })}+\mathrm{DIC}_{(\mathrm{C} \text { soft) }}$, and $\delta^{13} \mathrm{C}_{(\mathrm{DIC})}=\delta^{13} \mathrm{C}_{(\text {pref })}+\delta^{13} \mathrm{C}_{\text {(Csoft) }}$ to within

$80 \quad 0.03 \%$. That this error is not zero to within numerical precision, is due to the specific numerical scheme and implementation of the preformed and regenerated tracers in CGENIE. As described in the main text, for the preformed tracers, an anomaly is applied to each preformed tracer at the ocean surface at each time-step, equal to the difference between the current bulk tracer 
value and the preformed tracer value (as opposed to simply directly setting the values equal in the code). Because in the numerical scheme, all fluxes, including those induced by ocean circulation and any preformed tracer anomalies, are calculated simultaneously and only summed and applied to update the tracer concentration field at the very end of the model time-step, preformed tracer concentrations at the ocean surface and at the end of the timestep, never exactly equal those of the bulk tracer. The maximum error (ca. $-0.03 \%$ ) occurs at the surface of the Southern Ocean as a result of the energetic ocean transport environment (principally, convection) there. This error is propagated throughout the ocean, creating a mean ocean net error of $-0.012 \%$ in the diagnostic tracer scheme.

\section{Summary of calculated 'derived' tracers}

Although LOVECLIM is able to simulate preformed $\mathrm{PO}_{4}\left(\mathrm{P}_{\text {pref }}\right)$ and hence calculate regenerated

$95 \mathrm{PO}_{4}$ by differencing with (total) $\left[\mathrm{PO}_{4}\right]$, and then to $\mathrm{C}_{\text {soft }}$ by scaling with a $\mathrm{P}: \mathrm{C}$ ratio - see Menviel et al. [2015]), LOVECLIM was not run with this tracer included in the published deglacial experiment used in this study. Instead, $C_{\text {soft }}$ in LOVECLIM must be estimated from apparent oxygen utilization (AOU) (for example, as applied to output from the Bern3D model in Menviel et al. [2015]). To quantify the errors inherent in this approach, we calculate a number of derived tracer fields based on the primary (simulated) ones:

1. $\mathrm{O}_{2 \text { (sat) }}-\mathrm{O}_{2}$ solubility at every ocean grid point using ambient temperature and salinity values (plus density, $\rho$ ). For this, we calculate the solubility coefficient ( $\alpha$, mol kg-1 atm $^{-1}$ ) for $\mathrm{O}_{2}$ following Wanninkhof (1992) and using the coefficients from Millero and Sohn [1992], and assume an atmospheric partial pressure for oxygen $\left(p \mathrm{O}_{2}\right)$ of $0.2096 \mathrm{~atm}$ :

$\mathrm{O}_{2 \text { (sat) }}=\rho \times \alpha \times p \mathrm{O}_{2}$

(This diagnostic employs the exact same calculation as used 'normally' in cGENIE for simulating air-sea gas exchange (Ridgwell et al., 2007).)

2. AOU - calculated as the difference between $\mathrm{O}_{2 \text { (sat) }}$ and the actual model simulated tracer field of $\left[\mathrm{O}_{2}\right]$ :

$\mathrm{O}_{2 \text { (AOU) }}=\mathrm{O}_{2 \text { (sat) }}-\left[\mathrm{O}_{2}\right]$

3. AOU-P - regenerated $\mathrm{PO}_{4}$ - estimated from AOU divided by the assumed CGENIE $\mathrm{O}_{2}: \mathrm{P}$ Redfield ratio of (-)138:1:

$\mathrm{P}_{(\mathrm{AOU})}=\mathrm{O}_{2 \text { (AOU) }} / 138$

$115 \quad$ Note that for the purposes of this analysis, we ignore complications caused by the occurrence of sulphate reduction in oxygen minimum zones, meaning that locally, there will be a 'missing' fraction of regenerated phosphate that is not associated with AOU. For reference, the global oxygen consumption associated with particulate organic carbon oxidation in the preindustrial experiment is $608 \mathrm{Tmol} \mathrm{O}_{2} \mathrm{yr}^{-1}$, while (in the absence of nitrate reduction) while the global rate of $\mathrm{SO}_{4}{ }^{2-}$ consumption is 29 $\mathrm{Tmol} \mathrm{SO}_{4}{ }^{2-} \mathrm{yr}^{-1}$ (equivalent to $58 \mathrm{Tmol} \mathrm{O}_{2} \mathrm{yr}^{-1}$ ). However, this does not equate to a $\sim 10 \%$ global error in estimating AOU-P, because the re-oxidation of $\mathrm{H}_{2} \mathrm{~S}$ consumes dissolved oxygen, closing the AOU budget. Rather, the impact of not accounting for $\mathrm{SO}_{4}{ }^{2-} / \mathrm{H}_{2} \mathrm{~S}$ transformations will be a pattern of positive and negative error in estimating regenerated $\mathrm{PO}_{4}$ from $\mathrm{AOU}$. 
4. AOU-DIC - DIC regenerated from organic matter - estimated from AOU-P multiplied by the assumed cGENIE P:C Redfield ratio of 1:106:

$\mathrm{DIC}_{(\mathrm{AOU})}=106 \times \mathrm{P}_{(\mathrm{AOU})}$

This is an estimate of $C_{\text {soft. }}$.

5. AOU $-\delta^{13} \mathrm{C}$ - the $\delta^{13} \mathrm{C}$ contribution of DIC from regenerated from organic matter estimated by weighting the $\delta^{13} \mathrm{C}$ of POC exported from the overlying ocean surface $\left(\delta^{13} C_{(\text {Corg })}\right)$ by the fractional contribution of AOU-DIC to (total) DIC:

$\delta^{13} C_{(\text {AOU })}=\delta^{13} C_{(\text {Corg })} \times$ DIC $_{(\text {AOU })} / D I C$

This is an estimate of $\delta^{13} \mathrm{C}_{\text {(Csoft). }}$.

6. $\mathrm{C}_{\text {soft }}-\delta^{13} \mathrm{C}$ - the $\delta^{13} \mathrm{C}$ contribution of DIC from regenerated from organic matter estimated by weighting the $\delta^{13} \mathrm{C}$ of POC exported from the overlying ocean surface by the fractional contribution of $\mathrm{C}_{\text {soft }}$ to (total) DIC:

$\delta^{13} C_{(\text {(coft) }}=\delta^{13} C_{(\text {Corg })} \times$ DIC $_{(\text {Csoft })} / D I C$

This is an alternative estimate of $\delta^{13} \mathrm{C}_{\text {(Csoft) }}$ that is independent of the assumptions inherent in AOU. It also acts as a test of the assumption that one can tag regenerated carbon ( $\mathrm{DIC}_{(\mathrm{Csoft})}$ ) with the isotopic signature of POC exported from the overlying ocean in order to estimate regenerated $\delta^{13} \mathrm{C}$. Note that this post-processed diagnostic ( $\delta^{13} \mathrm{C}_{(\mathrm{Corg})}$-prime) is distinct from the explicitly simulated $\delta^{13} \mathrm{C}_{\text {(Csoft) }}$ tracer (see description of primary tracers).

145 For completeness, we also simulate but do not report, $\mathrm{P}_{(\text {pref), }}$ and from this derive regenerated $P\left(P\left(c_{(s o f t)}\right)\right.$ and hence can obtain a second alternative estimate of the $\delta^{13} C$ contribution of DIC from regenerated from organic matter $\left(\delta^{13} C_{\left.\left(C_{\text {oft }}\right)^{\prime \prime}\right)}\right)$.

All outputs are calculated on the basis of annual mean values of the 3D ocean tracer fields.

\section{Steady state analysis of the errors inherent in estimating $\mathrm{C}_{\mathrm{soft}}-\delta^{13} \mathrm{C}$}

150 We start our derived tracer analysis by illustrating the errors inherent in AOU itself. As is widely appreciated, AOU overestimates the consumption of oxygen through respiration as a consequence of incomplete equilibrium occurring between the ocean surface and overlying atmosphere which causes $\mathrm{O}_{2 \text { (sat) }}$ to be an overestimation of real ocean oxygenation. There is also an estimation error due to the non-linear solubility of oxygen, which follows a quasi-

155 exponential decay with increasing temperature. This results in an underestimate of AOU, because $\mathrm{O}_{2 \text { (sat) }}$ is underestimated when calculated from the ambient (linear mixing) temperature of parcel of water derived from sources equilibrated at 2 (or more) different sea surface temperatures. Figure $\mathrm{S} 4$ shows the difference between $\mathrm{AOU}$ and 'true' oxygen utilization (TOU), with the latter calculated as the difference between preformed $\left[\mathrm{O}_{2}\right]\left(\mathrm{O}_{2 \text { (pref) }}\right)$ and simulated ambient $\left[\mathrm{O}_{2}\right]$. From this it is clear that the disequilibrium error dominates, with the surface overestimate in AOU and its propagation into the ocean interior being particularly pronounced at high southern latitudes. While cGENIE calculates an AOU error about $30 \%$ smaller than originally reported by Ito et al. [2004] using the MIT OGCM, our results fall between the range of the different (higher resolution) models presented by Duteil et al. [2013]. 165 The zonal patterns calculated by cGENIE (Figure S4) are also similar to the Atlantic and Pacific sections presented in both papers (Ito et al. [2004], Duteil et al. [2013]). 
Converting AOU to AOU-C (the AOU-derived estimate of respired carbon - see above), translates to an error (overestimate) in $\mathrm{C}_{\text {soft }}$ of around $30 \mu \mathrm{mol} \mathrm{kg}{ }^{-1}$ and which dominates all of the deep Pacific and Indian Ocean below about 1000 m (Figure S6). (In cGENIE, the North

170 Atlantic Ocean surface is closer to equilibrium and full oxygenation and hence creates a plume of relatively low DIC error waters along the path of North Atlantic deep water.) However, we find that the $\delta^{13} \mathrm{C}$ error - the difference between explicitly simulated $\delta^{13} \mathrm{C}_{\text {(Csoft) }}$ and the AOUbased estimation (AOU $-\delta^{13} \mathrm{C}$ ), deviates noticeably from the pattern of the DIC error (Figure S5, $2^{\text {nd }}$ row down). Specifically: while the largest error in $\delta^{13} C_{(\mathrm{Csoft})}$ is indeed found throughout the

175 depth water column in the Southern Ocean, following the error in AOU and the $\mathrm{C}_{\text {soft }}$ field derived from this, the mid and low latitudes are characterized by much reduced error in $\delta^{13} C_{\text {(csoft) }}$ and deviate from the pattern of DIC error (top row). Somewhat enigmatically, a prominent $\delta^{13} \mathrm{C}_{\text {(Csoft) }}$ error maximum is also found throughout much of the water column in the North Pacific (but not at the northern-most end of the Indian Ocean). We resolve this by 180 differencing AOU $-\delta^{13} \mathrm{C}(\# 5)$ and $\mathrm{C}_{\text {soft }}-\delta^{13} \mathrm{C}(\# 6)$, whereby the error associated with assuming a fixed value field of $\delta^{13} C_{(P O C)}$ cancels out, leaving only the error in deriving $C_{\text {soft }}$ from $A O U$. This $\delta^{13} \mathrm{C}$ error field (Figure S5, $2^{\text {nd }}$ row from bottom) now visually correlates much more closely with the AOU DIC error field (top row). The $2^{\text {nd }}$ component to the total AOU based $\mathrm{C}_{\text {soft }}-\delta^{13} \mathrm{C}$ error can be calculated as the difference between 'true' (explicitly simulated) $\mathrm{C}_{\text {soft }}-\delta^{13} \mathrm{C}$, and $\mathrm{C}_{\text {soft }}-\delta^{13} \mathrm{C}$

185 estimated from $\mathrm{DIC}_{\text {(Csoft) }}$ together with $\delta^{13} \mathrm{C}_{(\mathrm{POC})}(\# 6)$. This is shown in the final row of Figure S5. Here, it can be seen that a significant positive error arises at mid-to-low latitude in the ocean subsurface.

What this analysis reveals is a flaw in how $\mathrm{C}_{\text {soft }}-\delta^{13} \mathrm{C}$ is being estimated by convoluting a field of exported $\delta^{13} \mathrm{C}_{\text {(POC) }}$ with $\mathrm{C}_{\text {soft. }}$. The 'true' $\mathrm{C}_{\text {soft }}-\delta^{13} \mathrm{C}$ tracer field is not only a product of local DIC

190 release (from organic carbon remineralization) with its associated local isotopic value $\left(\delta^{13} C_{(P O C)}\right)$, but also how the composition of a parcel of water is transformed as it moves through the deep ocean. The $\mathrm{C}_{\text {soft }}-\delta^{13} \mathrm{C}$ tracer field is hence an integrated history of isotopic remineralization, just as $\mathrm{C}_{\text {soft }}$ is an integrated history of bulk carbon remineralization. Importantly, in the real ocean, and to some extent simulated in many models including $C G E N I E, \delta^{13} C_{(P O C)}$ varies significantly 195 spatially: from values less than (more negative) than -30\%o towards the poles, to more (less negative) than $-20 \%$ at the equator. Hence, tagging an equatorial subsurface parcel of water with an equatorial-only $\delta^{13} \mathrm{C}_{(\mathrm{POC})}$ value omits the history of that water mass that will have started at high latitudes where initially it receives a much more isotopically depleted remineralized carbon input. Notably and rather more by luck than design, models either

200 assuming a fixed fractionation of POC $\delta^{13} \mathrm{C}$ Vs. DIC $\delta^{13} \mathrm{C}$, or like LOVECLIM, otherwise producing a relatively small pole-to-equator gradient in $\mathrm{POC} \delta^{13} \mathrm{C}$, will be subject to only a small associated error in convoluting exported $\delta^{13} \mathrm{C}_{(\mathrm{POC})}$ with $\mathrm{C}_{\text {soft }}$ (and leaving the related error related to the AOU approximation dominant everywhere).

\section{Transient $\mathrm{C}_{\text {soft }}-\delta^{13} \mathrm{C}$ error analysis}

205 So far, we have considered only a steady-state situation and the question arises: what happens during climate and carbon cycle change - do the error fields change and relatively by how much? For the final part of our diagnostic tracer framework analysis we turn to a simple transient simulation. For this, we take the same model preindustrial steady state, but apply 
(and hold) a radiative forcing at the top of the atmosphere equivalent to a doubling of

210 atmospheric $p \mathrm{CO}_{2}$ (to $556 \mathrm{ppm}$ ). The actual value of $p \mathrm{CO}_{2}$ simulated in the model is free to vary in response to the applied surface warming, but this does not affect the imposed radiative forcing. (Note that no injection of carbon to the atmosphere is used to induce the warming, and both bulk and ${ }^{13} \mathrm{C}$ carbon inventories are conserved between ocean+atmosphere as compared to the preindustrial spin-up.) The evolution over 2000 years of key global mean atmospheric

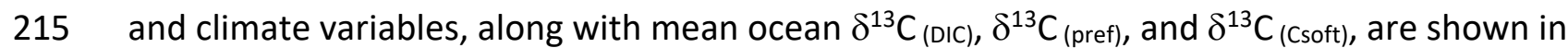
Figure S6. We pick 2 contrasting time-horizons to focus our final tracer analysis on: (1) 200 years, which corresponds in terms of time, to the 'rapid' interval from 16.3-16.1 ka of atmospheric $\delta^{13} \mathrm{C}$ decline recorded in ice-cores (and coincidently corresponds to the interval of most rapid $\delta^{13} \mathrm{C}_{\text {(pref) }}$ and $\delta^{13} \mathrm{C}_{\text {(csoft) }}$ change in our simple experiment), and (2) 2000 years, which

220 approximately corresponds to the overall 17.2 to $15 \mathrm{ka}$ early deglaciation interval. Note that imposing enhanced radiative forcing on a preindustrial state is not meant to replicate deglaciation. Rather, we deliberately create as simple a transient climate and carbon cycle change as possible for the purpose of assessing non steady-state diagnostic tracer behavior. However, although the warming does approximately correspond in overall magnitude to that

225 associated with deglaciation and is additionally associated with reorganization of the Atlantic Meridional Overturning Circulation as per the delgaciation, it should also be noted that this idealized instantaneous-perturbation transient experiment is distinct from the deglacial-like experiment described and analyzed in the main text.

Figure $\mathrm{S} 7$ shows the change in $\delta^{13} \mathrm{C}_{\text {(DIC) }}$ as compared to a control (continuing preindustrial)

230 experiment for year 200 (top) and 2000 ( $2^{\text {nd }}$-from-top row). In this specific idealized cGENIE model experiment, the patterns of change in $\delta^{13} C_{\text {(DIC) }}$ are dominated by changes in nutrient resupply to the ocean surface, and hence the strength of the biological export from the surface and organic matter remineralization in the ocean interior - all in turn reflected in changes in $\delta^{13} C_{\text {(Csoft) }}$ (not shown). In contrast, changes in $\delta^{13} C_{\text {(pref) }}$ (not shown) are largely confined to the

235 upper ca. $1000 \mathrm{~m}$ as a result of $\mathrm{CO}_{2}$ outgassing as the ocean warms. We also calculate how the error in $\delta^{13} C_{\text {(Csoft) }}$ as estimated from AOU changes - shown in the $2^{\text {nd }}$-from-bottom and bottom rows of Figure S7 for year 200, and 2000, respectively. We find that the isotopic error across the uppermost ca. $500 \mathrm{~m}$ depth in the model hardly changes as compared to the control (the close-to-zero anomaly values in Figure S7) and after 2000 years, as the system starts to re-

240 establish a steady state, the spatial distribution of the error anomaly largely follows that of the steady state AUO error (SI Figure 4).

\section{CGENIE $\mathrm{C}_{\text {soft }}-\delta^{13} \mathrm{C}$ analysis summary}

Relevant to the LOVECLIM model analysis conducted in the paper, we can conclude the following from the above experiments and analysis:

245 i. With a relatively minimal latitudinal gradient in the $\delta^{13} \mathrm{C}$ signature of exported POC in LOVECLIM, the error in estimating $\delta^{13} \mathrm{C}_{\text {(Csoft) }}$ and hence the relative contribution of $\delta^{13} C_{\text {(Csoft) }}$ vs. $\delta^{13} C_{\text {(pref) }}$ to a given simulated $\delta^{13} C_{\text {(DIC) }}$ change in LOVECLIM, will be dominated primarily by the error in estimating $\mathrm{C}_{\text {soft }}$ from AOU. (cGENIE, in contrast, sees approximately equivalent-in-magnitude error terms due to both error sources throughout the low and mid latitudes - Figure S5.) 
ii. At least in the context of the idealized transient experiment tested here, the AOUinduced $\delta^{13} \mathrm{C}_{\text {(Csoft) }}$ error is almost invariant throughout the uppermost ca. $500 \mathrm{~m}$ of the ocean (Figure S7). This is likely simply because the AOU error in $\delta^{13} \mathrm{C}_{\text {(Csoft) }}$ is close to zero in this region of the ocean to start with (Figure S5) and that AOU provides a relatively reliable means of estimating $C_{\text {soft }}$ here. The important point is that this is close to the depth range where planktic and (most) shallow benthic foraminifera are sampling the isotopic composition of DIC.

References:

Cao, L., Eby, M., Ridgwell, A., Caldeira, K., Archer, D., Ishida, A., Joos, F., Matsumoto, K., Mikolajewicz, U., Mouchet, A., Orr, J. C., Plattner, G.-K., Schlitzer, R., Tokos, K., Totterdell, I., Tschumi, T., Yamanaka, Y., and Yool, A.: The role of ocean transport in the uptake of anthropogenic $\mathrm{CO}_{2}, 6$, 375-390, https://doi.org/10.5194/bg-6-375-2009, 2009.

265

Duteil, O., Koeve, W., Oschlies, A., Bianchi, D., Galbraith, E., Kriest, I., and Matear, R.: A novel estimate of ocean oxygen utilisation points to a reduced rate of respiration in the ocean interior, Biogeosciences, 10, 7723-7738, https://doi.org/10.5194/bg-10-7723-2013, 2013.

Kirtland Turner, S. and Ridgwell, A.: Development of a novel empirical framework for interpreting geological carbon isotope excursions, with implications for the rate of carbon injection across the PETM, Earth and Planetary Science Letters, 435, 1-13, https://doi.org/10.1016/j.epsl.2015.11.027, 2016.

275

Ito, T., Follows, M. J., and Boyle, E. A.: Is AOU a good measure of respiration in the oceans?: AOU AND RESPIRATION, 31, n/a-n/a, https://doi.org/10.1029/2004GL020900, 2004.

280 Marsh, R., Müller, S. A., Yool, A., and Edwards, N. R.: Incorporation of the C-GOLDSTEIN efficient climate model into the GENIE framework: \&quot;eb_go_gs\&quot; configurations of GENIE, Geosci. Model Dev., 4, 957-992, https://doi.org/10.5194/gmd-4-957-2011, 2011.

Menviel, L., Mouchet, A., Meissner, K. J., Joos, F., and England, M. H.: Impact of oceanic 285 circulation changes on atmospheric $\delta^{13} \mathrm{CO}_{2}: \delta^{13} \mathrm{CO}_{2}, 29,1944-1961$, https://doi.org/10.1002/2015GB005207, 2015.

Ridgwell, A., Hargreaves, J. C., Edwards, N. R., Annan, J. D., Lenton, T. M., Marsh, R., Yool, A., 290 and Watson, A.: Marine geochemical data assimilation in an efficient Earth System Model of global biogeochemical cycling, 4, 87-104, 2007. 


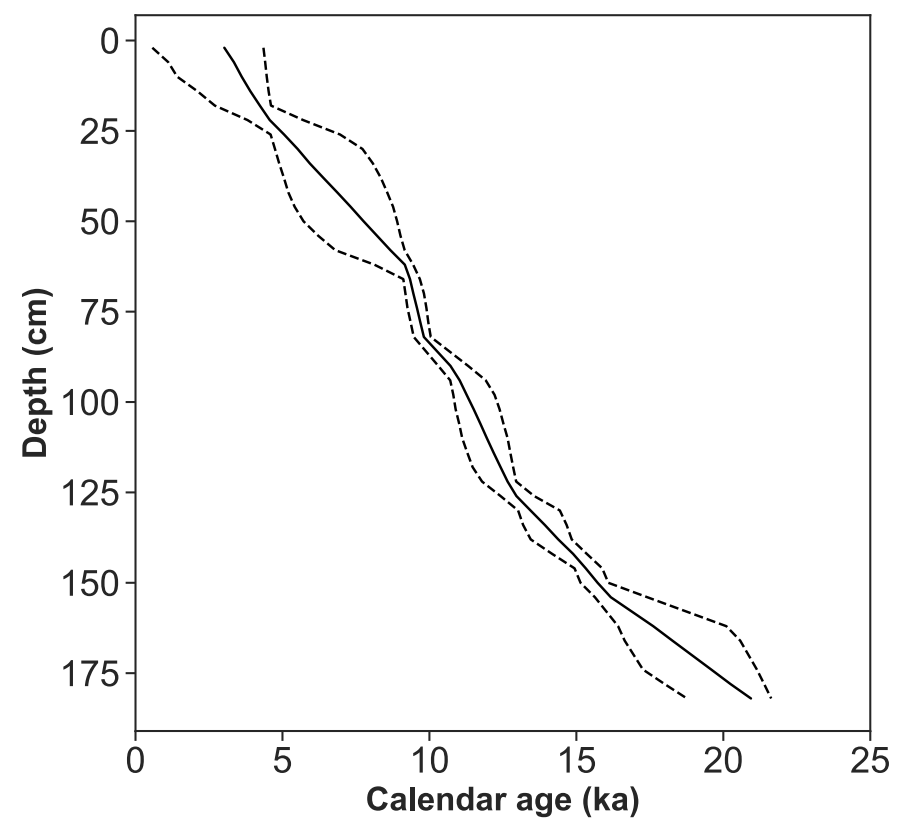

Figure S1. Age model of GeoB17402-2. The dash lines represent $2.5 \%$ and $97.5 \%$ quantile of 295 the assigned ages. 


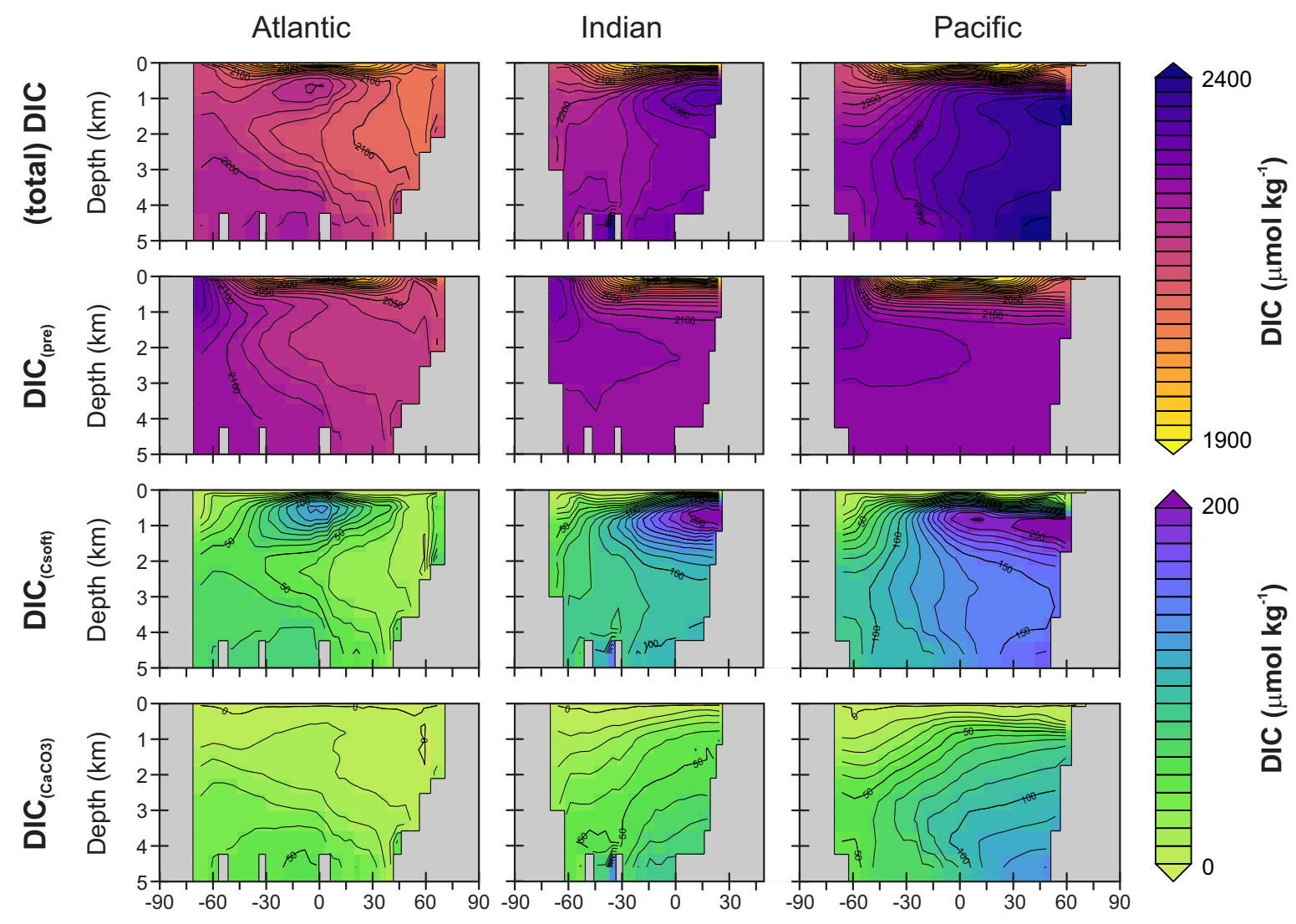

Figure S2. cGENIE preindustrial steady state, mean annual zonally averaged, DIC, DIC pref, DIC $_{\text {soft }}$ and $\mathrm{DIC}_{\mathrm{caco3}}$ distributions. 

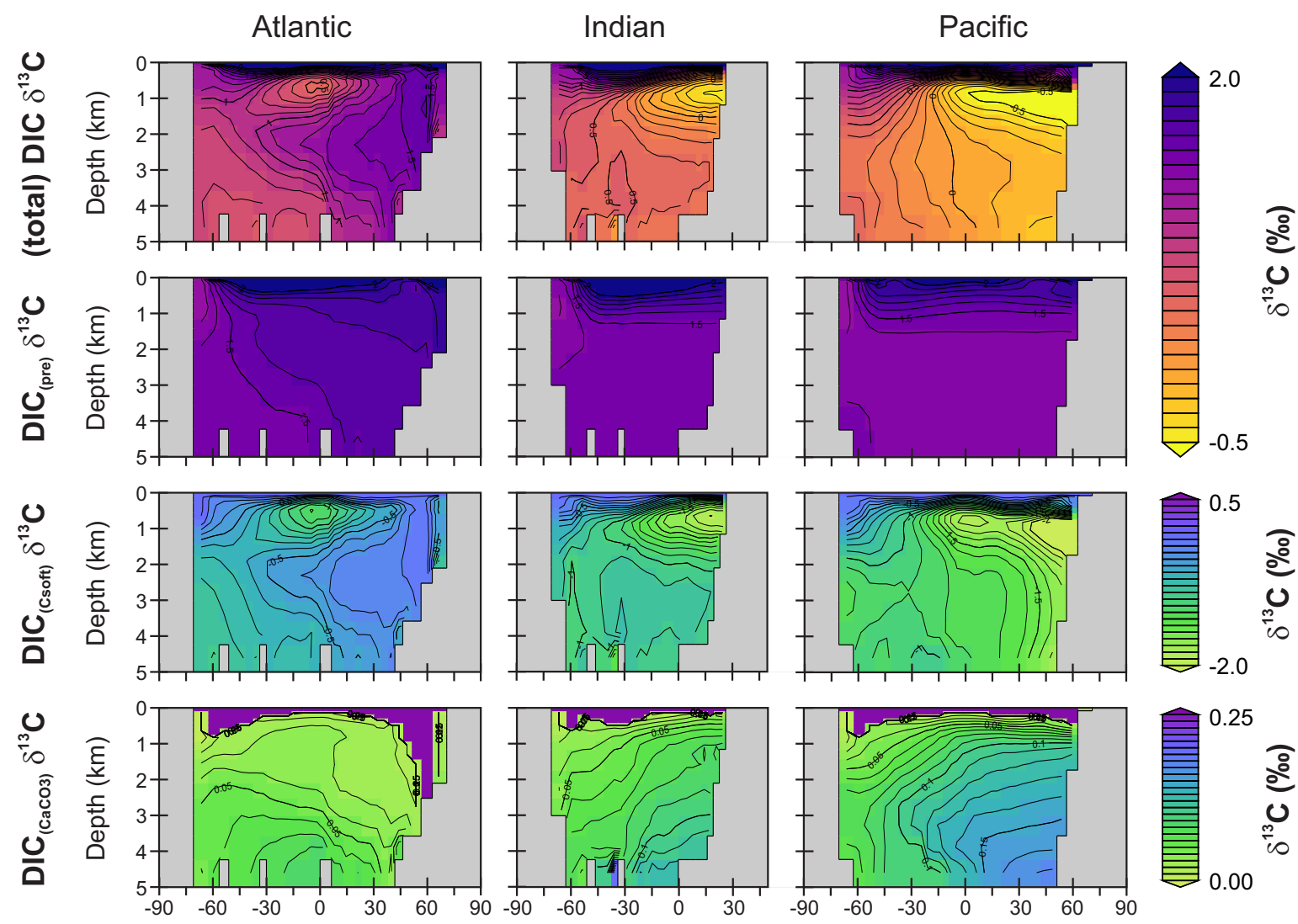

Figure S3. cGENIE preindustrial steady state, mean annual zonally averaged, distributions of the $\delta^{13} \mathrm{C}$ of DIC, DIC $\mathrm{pref}, \mathrm{DIC}_{\text {soft }}$ and DIC $\mathrm{Daco3}_{\text {. }}$ 


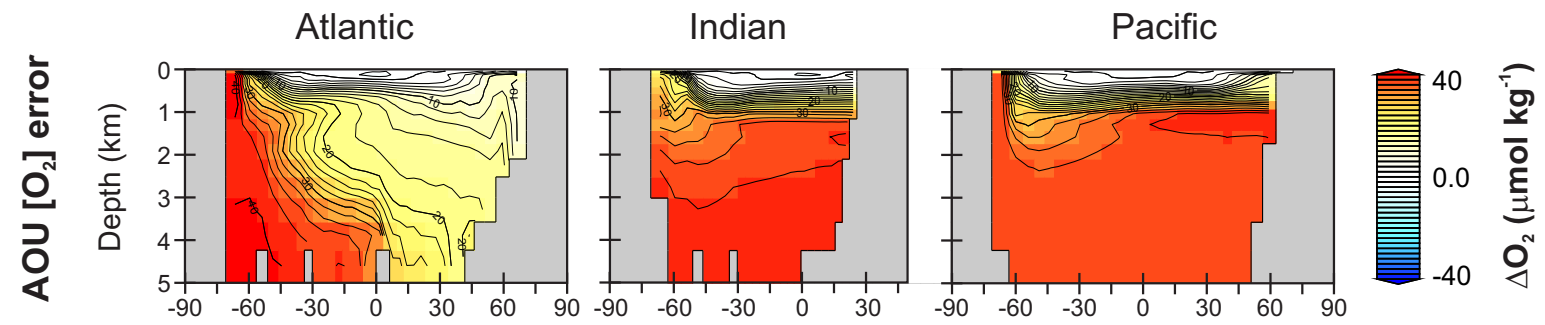

Figure S4. cGENIE preindustrial steady state AOU error analysis. 

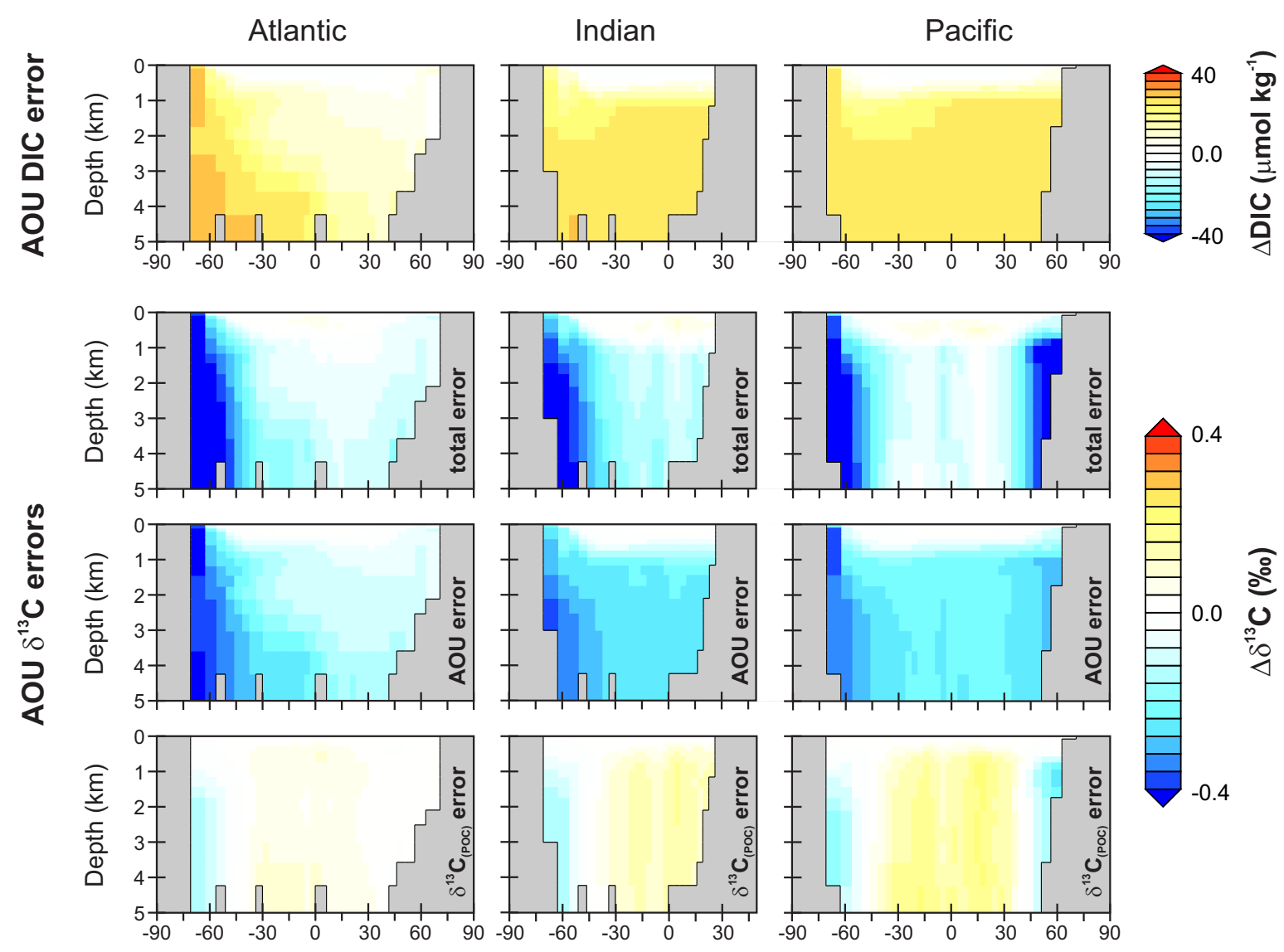

Figure S5. cGENIE preindustrial steady state AOU-based DIC and $\delta^{13} \mathrm{C}$ error analysis. 


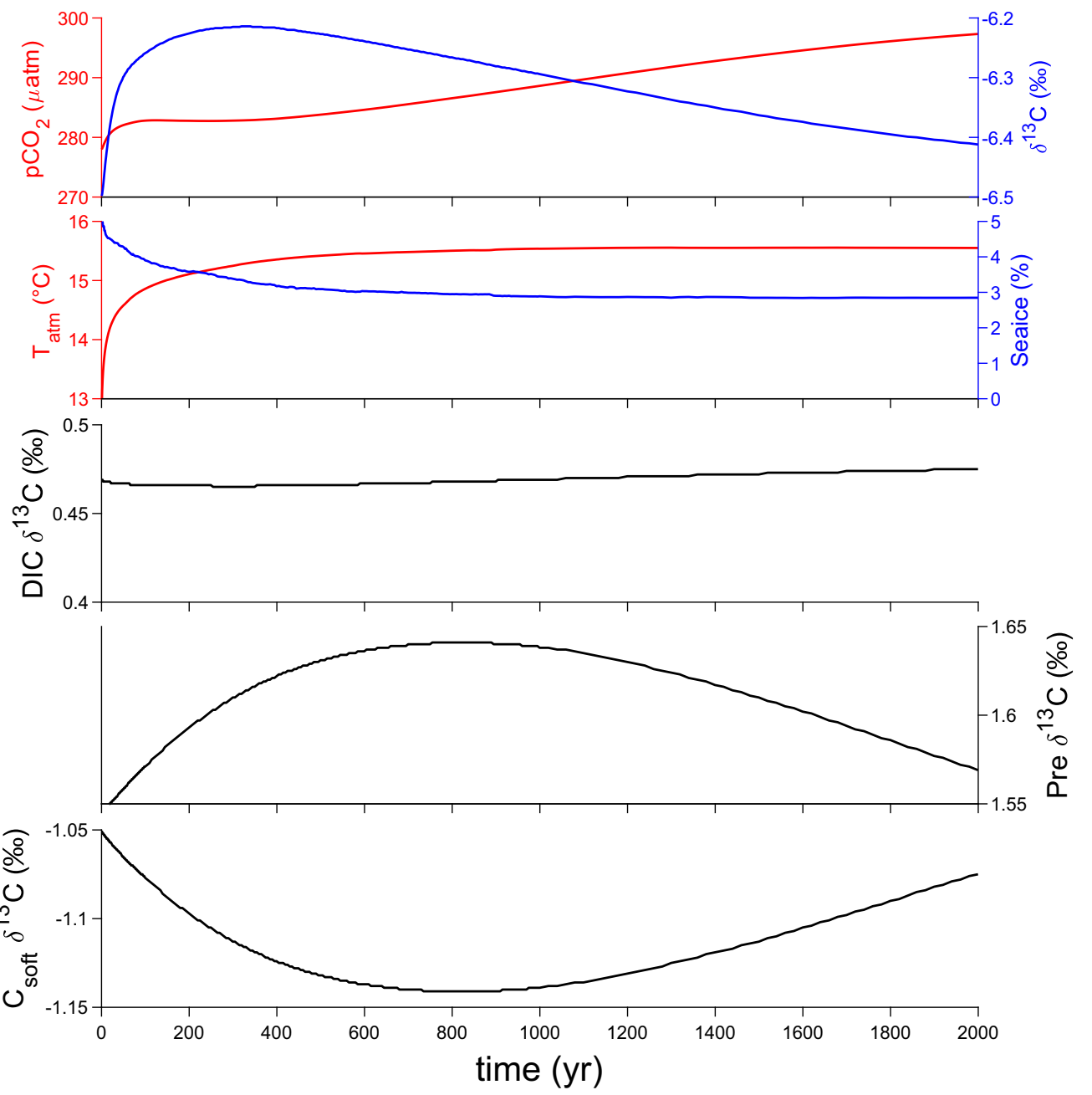

Figure S6. Time-series of cGENIE 2000-year idealized transient experiment. 

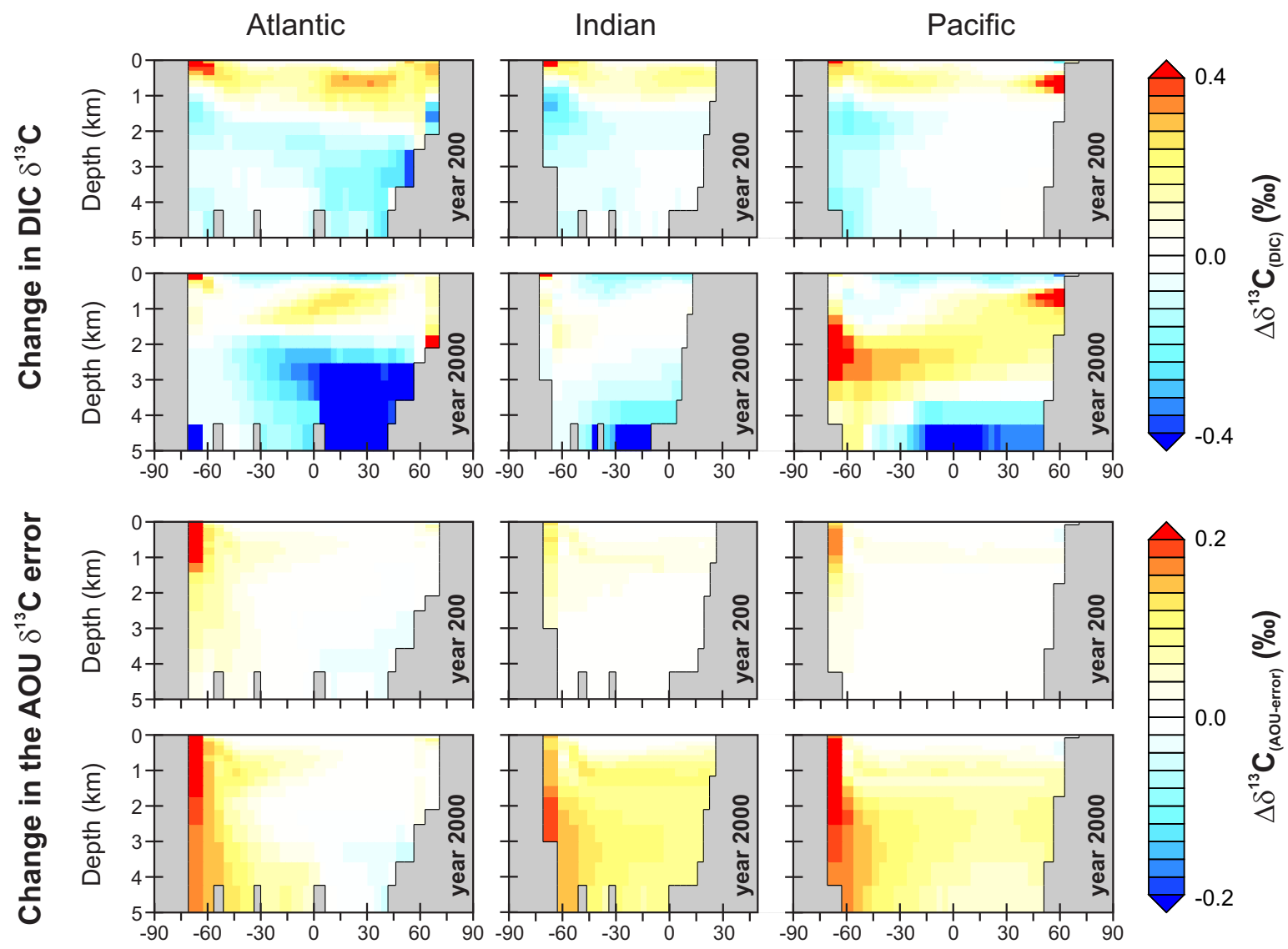

Figure S7. cGENIE 2000-year idealized transient experiment AOU error analysis. 

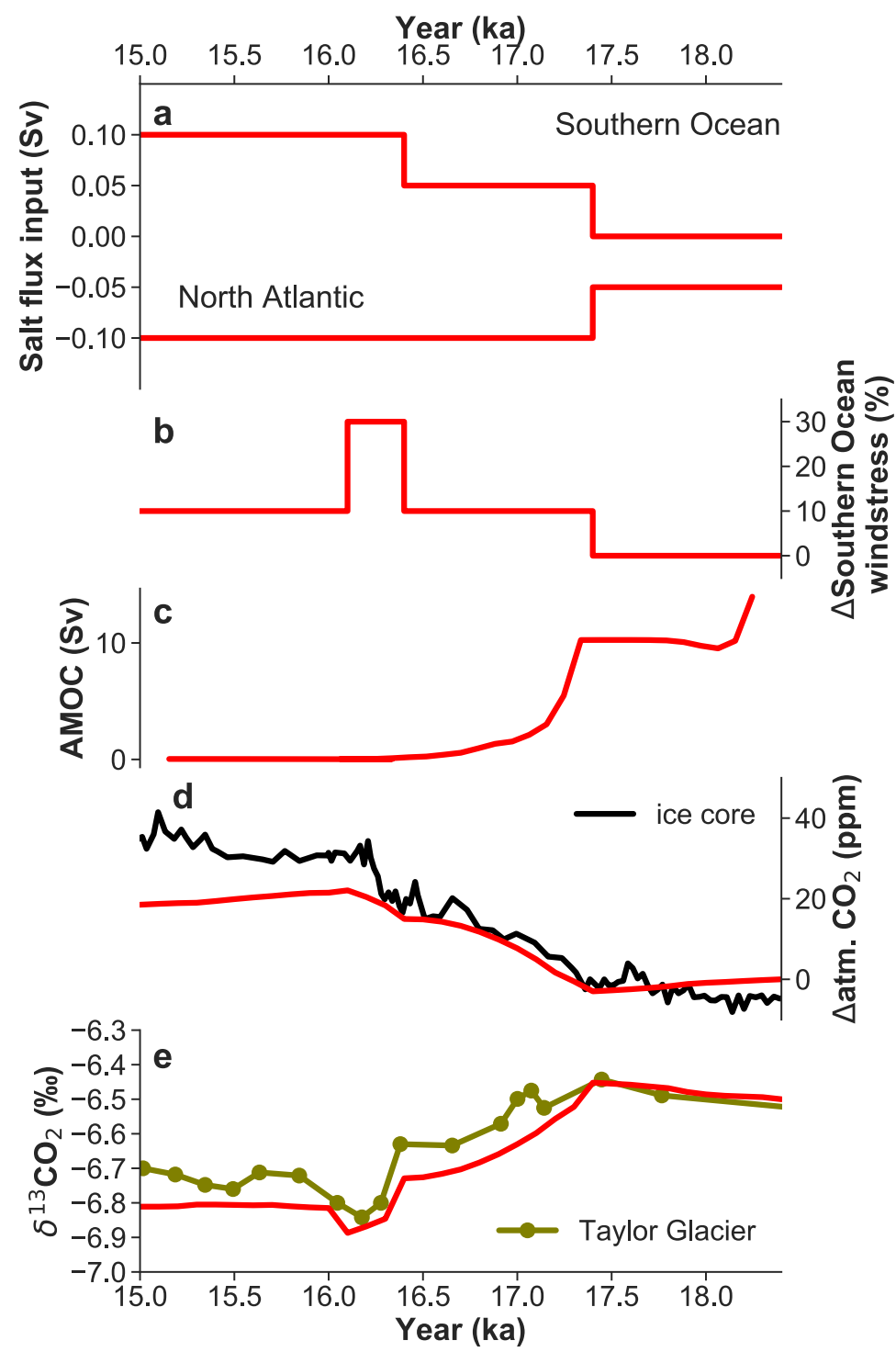

Figure S8. Forcing and atmospheric response in the cGENIE deglacial transient experiment. 


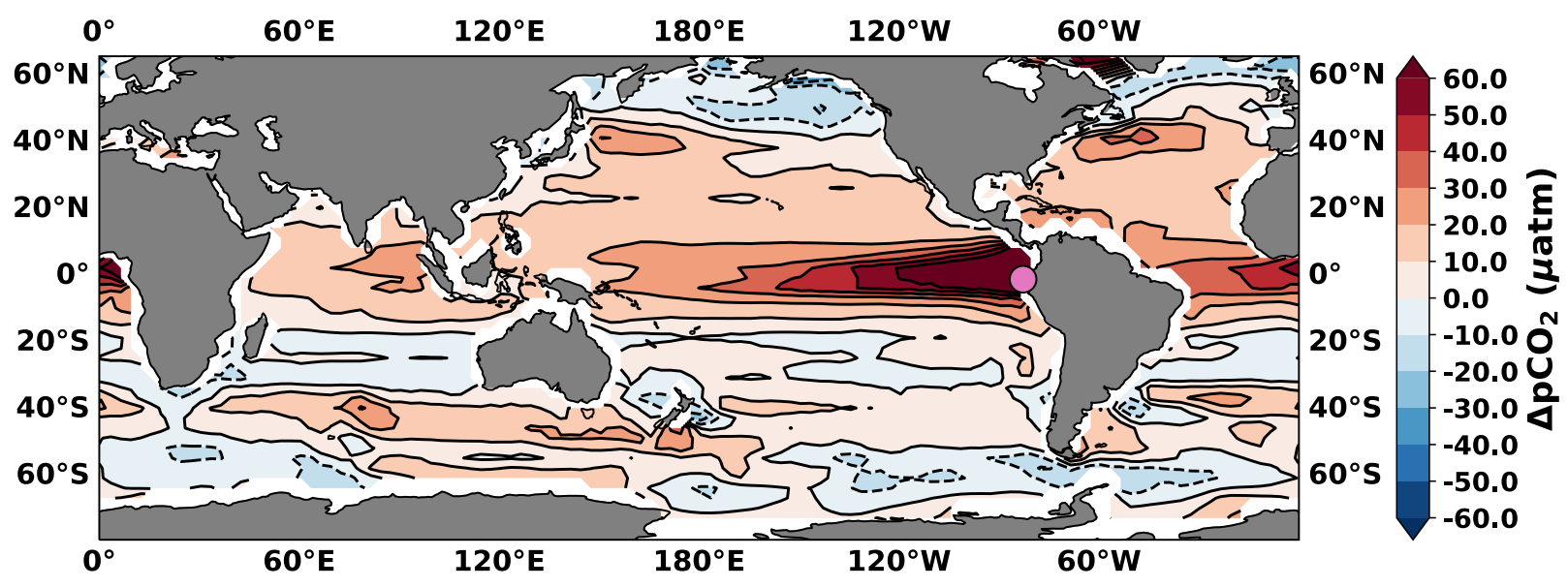

Figure S9. Air-sea pCO 2 gradient at 16 ka (i.e. Heinrich Stadial 1) simulated by

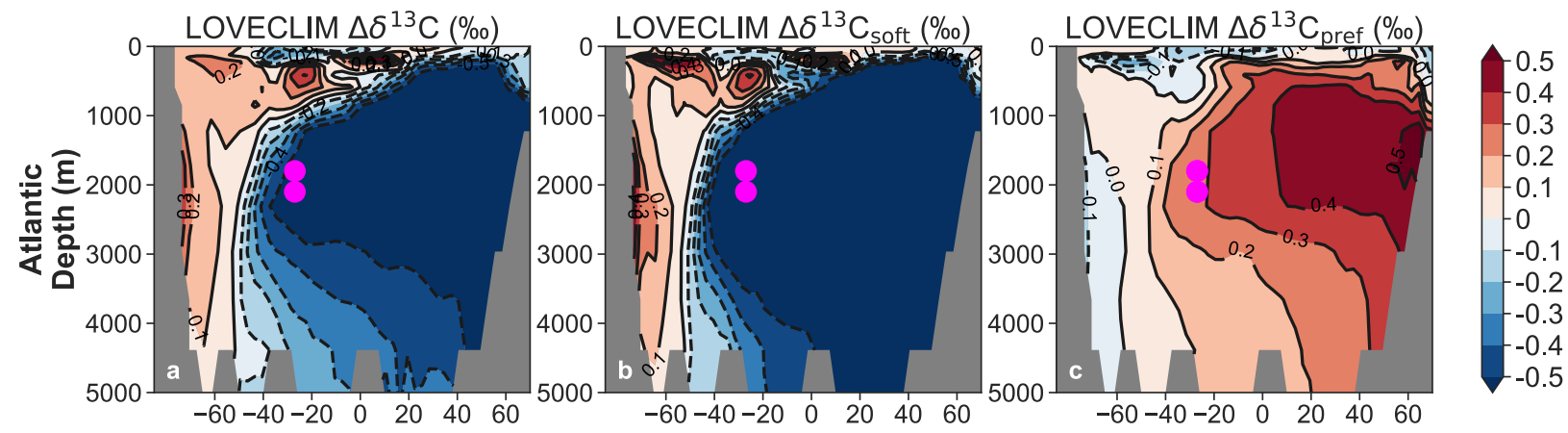

Figure S10. Atlantic zonal mean $\left(60^{\circ} \mathrm{W}-10^{\circ} \mathrm{W}\right)$ anomalies (15ka minus $\left.17.2 \mathrm{ka}\right)$ as simulated in LOVECLIM. The magenta circles mark the 78GGC and the 33GGC site. 